\section{Freedom of the mind got Nature banned by the Nazis}

SIR - Today, when freedom of the press and academia are in the news, along with the neglect or misuse of scientific results and theories by politicians, it may be useful to remember a time when political demagogy crushed these freedoms in Germany.

At the inauguration of the Philipp Lenard Institute in Heidelberg in 1936, German scientists and politicians started a campaign against Nature that succeeded in having the journal banned from libraries.

Nature's correspondents were accused of having created an anti-fascist espionage organization in Germany and Italy, starting in 1933. It was claimed in the science journal Zeitschrift für die gesamte Naturwissenschaft that Nature was filled with propaganda against the Nazi regime, " mostly based on democratic-liberal and Jewish feelings of hatred" (H. Rügemer Z. ges. Naturwiss. 3, $475-476 ; 1938)$. Leading articles such as "Freedom of the mind" (Nature 139, 941$942 ; 1937$ ) and "Science and peace" (Nature $139,979-981 ; 1937)$ were listed as examples.

${ }^{\alpha}$ When the abominable Jewish journal Nature speaks of the oppression of the spirit, it only means our termination, out of a sense of responsibility, of an activity by Jews and Jews-in-spirit directed at the destruction of the foundations of Aryan science in German culture," the Zeitschrift article concluded. The science minister, Bernhard Rust, took action.

"In the weekly science magazine Nature, appearing in London, papers are often published that contain outrageous and mean attacks on German science and the National Socialist state. Therefore, this journal must be expelled from general use in scientific libraries," he decreed in November 1937.

And expelled it was, until the end of the Second World War.

As this example shows, restricting academic freedom is a dangerous path to take. We need to resist all attempts to go down this road in the twenty-first century. Uwe HoBfeld*, Lennart Olssont *Ernst-Haeckel-Haus, Friedrich-SchillerUniversităt Jena, D-07745 Jena, Germany †Institut für Spezielle Zoologie und Evolutionsbiologiemit Phyletischem Museum, FriedrichSchiller-Universităt Jena, Erbertstraße 1, D-07745 Jena, Germany

\section{Iran: support for science does not outweigh crimes}

SIR - I was horrified to read the text of your Editorial "Revival in Iran" (Nature 442, 719-720; 2006). I cannot comprehend how one of the world's leading scientific journals could publish an article calling for scientists to adopt a benign attitude towards the present Iranian regime.

I was impressed by the sentence in the Editorial citing the fact that one of the current government's "first acts was to wipe out the debts accrued by universities".

Nevertheless, President Mahmoud Ahmadinejad of Iran has also called publicly for my own country to be "wiped out ${ }^{\prime \prime}$ from the map of the Earth. He has also been a consistent Holocaust denier, even organizing an exhibition of cartoons poking fun at the Holocaust.

At the same time, human rights are being trampled in Iran, as noted by independent organizations such as Amnesty International (see http://web.amnesty.org/report2006/ irn-summary-eng). The regime commits many other crimes at home and abroad; it is described by the US State Department, for example, as the world's "most active state sponsor of terrorism" (see www.state.gov/r/ $\mathrm{pa} / \mathrm{scp} / 2006 / 65559 . \mathrm{htm}$ ).

One needs a unique degree of detachment to commend the regime for a presumably liberal attitude to science and higher education, while looking away from the dominant aspects of its essence and policies. I strongly urge Nature to reconsider its position.

Itamar Rabinovich

Office of the President, Tel Aviv University, Tel Aviv 69978, Israel

Several other correspondents have written to make similar points - Editor, Nature.

\section{Iran is sixth, not second, in Middle East publication list}

SIR - Your Editorial "Revival in Iran ${ }^{\circ}$ (Nature 442, 719-720; 2006) states that, in the 1990s, "Iran became the most scientifically productive country in the Middle East apart from Israel'. This is a misleading statement, true only when ignoring relative population size.

With a population of 68 million, Iran is the second largest country in the Middle East. It is impossible to compare small countries such as Lebanon, with 3.9 million inhabitants, or Jordan ( 5.9 million) to one that is 10 times more populous by merely counting the number of scientific publications. Population size should be normalized.

When the number of publications (see www.ncbi.nlm.nih.gov/entrez) is corrected for population size, Iran becomes only the sixth in terms of scientific productivity. Israel, Kuwait, Lebanon, Jordan and Saudi Arabia top the list.

EranMeshorer

National Cancer Institute, National Institutes of Health, 41 Library Drive, Bethesda,

Maryland 20892, USA

\section{Iran's progress towards nuclear capability is no joke}

SIR - One might have thought it was 1 April, rather than 17 August, on reading your indefensible celebration of Iran's nuclear programme, supposedly promoting science and education ( ${ }^{\alpha}$ Revival in Iran ${ }^{\prime}$ Nature 442, $719-720 ; 2006)$. Perhaps when the fruit of this programme explodes in London, you will be writing an explanation of the humanistic ethics involved.

Guy Goodw in

University Department, Warneford Hospital, Oxford OX3 7JX, UK

\section{Taking time to savour the rewards of slow science}

SIR - As an older, experienced, part-time postdoctoral fellow, I have observed a trend amongst my younger, more vigorous colleagues to experiment themselves into oblivion. Following the lead of the 'slow food' movement, I suggest we adopt a philosophy of 'slow science' to address this issue, which I believe is damaging the very basis of scientific enquiry.

My personal choice has been to accept the here and now - I am here, making history, so why not enjoy this journey? I may not be here in six months, twelve months, two years, but I am not going to work 100 hours a week to try to attain the elusive goals of my own grant, my own lab, perhaps even tenure.

In shedding the ambition of my peers, I have discovered a secret: science, slow science, is perhaps the most rewarding and pleasurable pastime one could ever hope for. My supervisor's lab is small - two postdocs only, with no teaching responsibilities. We are free to read the literature, formulate ideas and carefully plan our experiments so as to execute thoughtful strategies. We do not plough through genomes hoping to discover something interesting; we formulate a theory, and then we go in and test it.

Perhaps we are old-fashioned, but I feel my education as a scientist has benefited far more from my five years of slow science than the preceding five years of fast science. What's more, we are on the brink of something big, exciting and wonderful, that spurs my slow science forever onwards.

Lisa Alleva

School of Biochemistry and Molecular Biology, The Australian National University, Canberra, ACT 0200, Australia

Contributions to Correspondence may be submitted to corres@nature.com. They should be no longer than $\mathbf{5 0 0}$ words, and preferably shorter. Published contributions are edited. 